\title{
Urgences
}

\section{Shoshana Felman, La folie et la chose littéraire, Paris, Seuil, coll. " Pierres vives ", 1978, 351 p.}

\section{Christiane Asselin}

Numéro 13, mars 1986

\section{Éclats d'atelier}

URI : https://id.erudit.org/iderudit/025254ar

DOI : https://doi.org/10.7202/025254ar

Aller au sommaire du numéro

\section{Éditeur(s)}

Urgences

\section{ISSN}

0226-9554 (imprimé)

1927-3924 (numérique)

Découvrir la revue

Citer ce compte rendu

Asselin, C. (1986). Compte rendu de [Shoshana Felman, La folie et la chose littéraire, Paris, Seuil, coll. " Pierres vives ", 1978, 351 p.] Urgences, (13),

122-122. https://doi.org/10.7202/025254ar d'utilisation que vous pouvez consulter en ligne.

https://apropos.erudit.org/fr/usagers/politique-dutilisation/ 


\section{“ÉCRIRE AUJOURD'HUI, Au- toportraits d'écrivains sur fond de siècle", Autrement, Paris, no. 69, avril 1985, 253 p.}

Présentation soignée, recherche d'une certaine position d'avant-garde, parti pris pour les pratiques innovatrices, diversité des approches et éclectisme, Autrement est une revue française "branchée" qui interroge les phénomènes sociaux et cuiturels contemporains: danse, mode, homosexualité, publicité, couples, art, télévision. etc. Dans ce numéro mettant en scène l'écriture, une cinquantaine d'écrivain-e-s français et étrangers fentre autres: Sollers, Le Clézio, Anne Hébert. Meschonnicl et quelques artistes, musiciens et éditeurs nous font lire l'objet écrit et ses lignes de force lles revues littéraires, l'écriture et l'ordinateur, l'objet-livre, le métier d'écrivaine, le travail d'écriture, etc.). Fictions (prose et poésiel, textes de réflexion théorique, entrevues, en tout près de soixante-dix textes qui nous font entrer dans les coulisses de la fabrique d'écriture, côté cour et côté jardin, histoire de savoir un peu pourquoi et comment écrire aujourd'hui.

Marie Bélisle

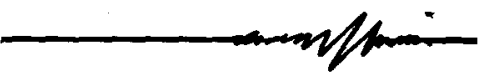

Shoshana Felman: La folie et la chose littéraire, coll. "Pierres vives", Paris, Seuil, 1978, $351 \mathrm{p}$.

Folie et littérature ont, depuis toujours, partie liée. En marge l'une de l'autre, elles s'appellent et s'excluent réciproquement. Cette relation pour le moins ambiguë a intéressé maints auteurs dont Shoshana Felman, Juive américaine, spécialiste de la littérature française. Dans La folie et la chose littéraire, elle nous livre son point de vue, théorique et critique, sur la folie de l'écriture et l'écriture de la folie.

Pour Feiman, folie et littérature s'appréhendent comme une quête de l'étrange et de l'étranger, comme un cheminement à l'intérieur du langage. $\mathrm{ki}$, il ne s'agit plus de lire, mais de dé-lire, de dé-lier et de dé-régler. La folie semble une voie de la connaissance, un autre mode d'exploration de la différence instituée par le langage. Aussi, Felman nous ramène-t-elle, par le biais d'analyses du discours poétique, du roman et de la psychanalyse, à la frontière du champ littéraire, là où se jouent les répertoires d'une folie qui est "lieu commun", c'est-à-dire "lieu d'inclusion, dedans d'une culture" (p. 13). Son but principal sera donc d'ouvrir ce champ à la question de la folie, afin de penser autrement la littérature et les études littéraires. Ce but atteint, folie et littérature se rejoindraient pour s'éclairer mutuellement car, "s'il existe (...) quelque chose comme la chose littéraire, elle ne peut s'expliquer que par la folie (...) mais en vertu d'une irréductible résistance de la chose à l'interprétation" (p. 349).

La folie dont nous parle Felman, ce n'est ni celle que l'on enferme ni cette "hallucination des mots", mais plutôt une réponse de l'homme à la "question du mot".

Christiane Asselin

\section{Annie Cohen-Solal. Sartre 1905-1980, Paris, Gallimard, 1985, $728 \mathrm{p}$.}

Écrivain de la démesure, dont la vie de colosse infléchit le gigantisme et l'envergure de l'oeuvre, tel est le Sartre que nous 